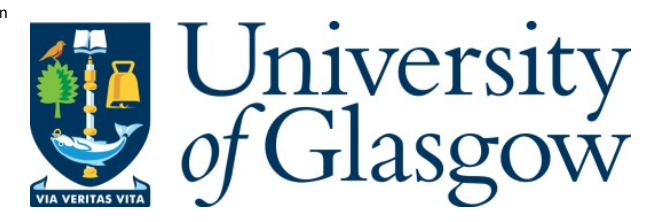

Noble-J ones, R., Fitzpatrick, B., Sneddon, M . C., Hendry, D. S., and L eung, H. Y., (2014) D evelopment of the Lymphoedema G enito-U rinary Cancer Q uestionnaire. B ritish J ournal of Nursing, 23 (S18). pp. 14-19. ISSN 09660461

Copyright @ 2014 M ark A llen Healthcare

A copy can be downloaded for personal non-commercial research or study, without prior permission or charge

Content must not be changed in any way or reproduced in any format or medium without the formal permission of the copyright holder(s)

http://eprints.gla.ac.uk/97995/

Deposited on: 30 October 2014

Enlighten - Research publications by members of the University of Glasgow http://eprints.gla.ac.uk 
Article published: B ritish J ournal of Nursing Urology Supplement 23(18): S14-S19. Oct

2014

\title{
Development of the Lymphoedema Genito-Urinary Cancer Questionnaire
}

\section{(LGUCQ)}

\begin{abstract}
The aim of this study was to develop a patient self-report tool to detect symptoms of genital and lower limb lymphoedema in male survivors of genitourinary cancer. The study incorporated the views of patients and subject specialists (lymphoedema and urology) in the design of a patient questionnaire based on the literature. Views on comprehensiveness, relevance of content, ease of understanding and perceived acceptability to patients were collated. The findings informed the development of the next iteration of the questionnaire. The overall view of participants was that the development and application of such a tool was of great clinical value and the Lymphoedema Genito- Urinary Cancer Questionnaire (LGUCQ) has significant potential for further development as a research tool to inform prevalence of this under-reported condition.

Key words: Genitourinary cancer Lymphoedema Self report Early diagnosis Symptom assessment
\end{abstract}

\section{Background}

Lymphoedema is a debilitating, chronic condition which, if untreated, may progress to chronic inflammation, infection and hardening of the skin (Rockson 2009). This can result in further lymph vessel damage, disfigurement and decreased function of the affected body parts. The negative impact of lymphoedema on the physical, psychological and social quality of life of affected individuals can be huge (Morgan et al 2005; Ridner 2009). The management of repeated episodes of infection and advanced lymphoedema also has a financial cost to health and social care services (Todd et al 2010; Stout et al 2012). Although there have been recent advances in understanding of lymphoedema in relation to its pathophysiology, diagnosis and treatments, it remains an incurable condition (Rockson 2012). Consequently, treatment relies on early diagnosis, when intervention is most effective in managing symptoms and preventing complications (Stout Gergich et al 2008).

To date, most of the research on lymphoedema has focused on its manifestation in relation to breast cancer and its treatment (Cormier et al 2010; Bernas 2013). This has not only led 
to improved mechanisms for diagnosing and treating lymphoedema for this group of patients (S tout Gergich et al 2008; Torres Lacomba et al 2010), but also to improved cancer treatment techniques. For example, sentinel lymph node dissection as an alternative to standard axillary lymph node dissection (Sakorafass et al 2007; Cowher et al 2014).

By contrast, there is a paucity of research on lymphoedema in relation to other cancer sites, particularly male genitourinary cancer (Cormier et al 2010). The incidence of lymphoedema in relation to genitourinary cancer and its treatment varies according to the richness of the adjacent lymphatic system to the affected site. A systematic review and meta-analysis reported incidences of $21 \%$ for penile cancer, $16 \%$ for bladder cancer and $4 \%$ for prostate cancer (Cormier et al 2010). These figures are based on a very small number of studies and which, with the exception of one that used penile circumference measurement, utilised subjective approaches to symptom assessment.

The most significant risk for lymphoedema however is inguinal lymph node clearance for penile cancer ( $R$ imouche et al 2013). In contrast, whilst the incidence of lymphoedema in patients following treatment for testicular cancer is unknown, it is thought to be rare (Okeke et al 2004). Depending on the stage of the testicular cancer, treatment may involve radiotherapy or lymph node dissection, both of which have a theoretical risk of lymphoedema. Treatment of the other genito-urinary cancers (prostate, bladder and penile) usually involve surgery, with the possibility of follow up radiotherapy. The risk of lymphoedema therefore will depend on the position and extent of both treatments.

Surgical techniques continue to improve however, it is widely accepted that the true incidence and prevalence of lymphoedema following cancer treatment is underestimated, and is frequently under recognised or misdiagnosed (Rockson 2008; Bernas 2013). Identification of previously undetected lymphoedema has the potential to give more accurate figures on incidence in this group as a whole and with additional patient data, incidence figures of particular subgroups. This would enable advice, education and surveillance to be targeted more accurately and thereby more efficiently.

\section{Aim and objectives of the study}

The overall aim of this study was to develop a patient self-report tool that could be used to detect symptoms of genital and lower limb lymphoedema in male survivors of genito-urinary cancer.

The specific objectives were: 
1. to construct the first prototype of the Lymphoedema Genito-urinary Cancer Questionnaire (LGUCQ) from the existing evidence-base, and

2. to obtain and incorporate academic, clinical and patient views into the next prototype of the LGUCQ.

\section{Methods}

This study involved two distinct but complementary phases to incorporate the existing evidence with the views of patients and subject specialists (in both lymphoedema and urology) in the design and content of a patient self-administered screening tool.

Phase 1 comprised a review of published and unpublished literature to identify pre-existing assessment tools and evidence relevant to symptoms of lymphoedema. The electronic data bases used for the initial literature search were Medline, CINAHL,EMBASE, Pedro and the collection of databases EBCSO Health Source: Nursing/Academic Edition. The searches were limited to 2002 - 2013 and English Language publications. The search terms used were lymphoedema/ lymphedema, genito-urinary/genitourinary/ urogenital cancer, assessment/ self-report/ patient report. This search strategy identified 14 possible studies which on closer review reduced to only 4.

The search was then expanded through a hand search and a call out through national and international special interest groups in lymphoedema and in urology for grey literature. Only one further tool was found but this was an algorithm for differential diagnosis rather than a self-report tool.

A content analysis of existing tools was then performed to assess their relevance and utility to potential symptoms of genitourinary lymphoedema. This provided the foundation for the first iteration of the LGUCQ which then underwent refinement with the research team comprising a lymphoedema specialist, an experienced researcher and two consultant urologists.

P hase 2 comprised sending the first iteration of the LGUCQ to a purposive sample of lymphoedema specialists, consultant urologists and male genitourinary cancer survivors within four Scottish Health Boards, incorporating all three Managed Clinical Networks for Genitourinary Cancer in Scotland. The patient participants included men who were living with a diagnosis of genitourinary related lymphoedema and some who had no identified lymphoedema. 
In this study a diagnosis of lymphoedema was based on a persistence of swelling beyond the stage of post-operative/treatment oedema and in the absence of other local or central causes of oedema. The presence or absence of lymphoedema was not confirmed by independent physical assessment.

Patients were eligible to participate if they were:

- male,

- aged 18 years or older

- English speaking

- were at least 2 months post operative from surgical intervention for cancer of the bladder, prostate, testes or penis

Patients were excluded if they:

- were currently receiving or expected to receive further genitourinary cancer-related surgery, chemotherapy or radiotherapy

- had pre-existing lymphoedema/chronic oedema of the lower limbs/genitalia prior to their genitourinary cancer treatment

- were unable to give informed consent

Patients were first approached about the study by their urology consultant. With their permission, the contact details of interested patients were then sent by the consultant urologist to the researcher.

A series of individual semi-structured face-to-face or telephone interviews were conducted with the practitioner and patient participants by one researcher (RN-J). Participants' views were sought on the first iteration of the LGUCQ in relation to the comprehensiveness and relevance of its content, ease of understanding and perceived acceptability to patients. In addition the patients were asked about their experiences in relation to the identification of lymphoedema where this applied.

With the participant's permission the interviews were audio recorded. The recordings were transcribed verbatim by the researcher. A depersonalised copy of the transcription of their interview was sent to participants in order to verify content. The data were analysed using a framework approach (Pope et al 2000). This involved 5 steps:

- Familiarisation 
- Identification of themes

- Indexing

- Charting and Mapping

- Interpretation

The data analysis was undertaken independently by two of the authors ( $R \mathrm{~N}-\mathrm{J}$ and MS). The findings were then used to inform the construction of the subsequent iteration of the LGUCQ (Appendix 1).

Ethical approval was given by the University of Glasgow, College of Medical, Veterinary \& Life Sciences Ethics Committee for Non-Clinical Research Involving Human Subjects. In addition the study was registered with the clinical governance/effectiveness bodies of four health boards, Greater Glasgow \& Clyde, Highland, Lothian and Tayside.

Funding for this study was provided by the Lymphoedema Research Fund (UK) and the British Lymphology Society (Caroline Badger Research Fund Award).

\section{Findings}

\section{Phase 1}

\section{Literature review and expert consultation}

There is a dearth of published literature which specifically addresses the self-assessment or self-report of lymphoedema in relation to genitourinary cancer. In contrast there are a number of assessment tools for breast cancer related lymphoedema (BCRL) (Viehoff et al 2013). The purpose of the questionnaires varied however with many being for assessing the extent of symptoms in known cases of BCRL or quality of life measures rather than being screening / self-report tools for the condition.

The most widely used self-report tool for assessing symptoms of upper extremity lymphoedema was the Lymphoedema Breast Cancer Questionnaire (LBCQ) (Armer et al 2003). The most helpful self-report descriptors for BCRL were reported as being 'heaviness, swelling and numbness' (Armer et al 2003). Similarly a study by Langbecker et al (2008) reported that the descriptors used by lymphoedema specialists also included 'swelling' and 'heaviness', however 'tightness' and 'skin problems' were used in a higher proportion of lower limb patients and they were more likely to be presenting later with problems.

The LBCQ provided the foundation for the development of an instrument for assessing symptoms of lower extremity lymphoedema in women, the Gynecological Cancer 
Lymphoedema Questionnaire (GCLQ) (Carter et al 2010). For the group of women studied (those treated for cervical, uterine or vulvar cancer), the GCLQ effectively differentiated between those who did and did not have lymphoedema. The pilot study did not claim that the tool had predictive value or was able to identify the early signs of lymphoedema but it supported the descriptors in the existing literature for identified lymphoedema and the 'heaviness, swelling and numbness' reported in untreated lymphoedema.

Subsequently Yost el al (2013) developed a screening tool for lower limb lymphoedema in normal weight and, uniquely, obese women but which was not specifically aimed at those treated for gynaecological cancers. Predictably the ability of the questions to identify lower limb lymphoedema was worse among obese women, particularly the specificity of identifying those without lymphoedema.

\section{Designing the LGUCQ prototype}

The most obvious difference in this study compared to the above studies is the gender. This is pertinent to design as it has been established that compared to women, men are less likely to read instructions in health literature (Witty et al 2014). Moreover it may be important to distinguish between different parts of the genitals when assessing male genital lymphoedema in order to establish the cause ( $G$ araffa et al 2008). Establishing which terms are most meaningful to the target audience e.g. 'penis and scrotum' as opposed to 'genitals' may also be crucial. The prototype therefore included both forms in various combinations in order to explore understanding and acceptability. An additional consideration was the abundance of colloquial terms for male genitals that might give rise to confusion. To overcome this, it was decided that the first iteration of the screening tool should contain both text and illustration to overcome potential barriers relating to terminology.

The Yost et al (2013) tool was taken as the starting point for development, as the GCLQ was considered too detailed to be used primarily as a self-report screening tool. The apriori characteristics were that the tool should be easy to complete and acceptable in language and appearance to the target population, content reflective of the symptoms described in the literature and in the experience of experts, and no longer than 2 sides of standard A4 paper.

Reflecting previous tools, questions were included concerning the extent of swelling as perceived by the patient, symptoms other than swelling and functional effects of the symptoms. In addition 4 questions were added at the request of the expert panel in relation to broader quality of life issues. An effect on quality of life is noted for both lymphoedema and genito-urinary cancers and their treatment (Morgan et al 2005; Gilbert et al 2007). 
Heaviness, swelling and tightness were descriptors carried into the first iteration of the LGUCQ tool based on the literature reviewed. Numbness and the medical descriptor 'altered sensation' used by the expert panel were replaced by 'strange sensation'; this and 'aching / discomfort' were added to the prototype tool for evaluation. At this stage the tool was envisaged as being first used within a year of genito-urinary cancer treatment therefore the skin changes characteristic of long term lymphoedema were thought unlikely (International Society of Lymphology 2003).

\section{Phase 2}

A total of 19 participants were interviewed regarding the prototype questionnaire from across four Scottish Health Boards areas, incorporating all three Managed Clinical Networks for Genitourinary Cancer in Scotland. The participants represented three groups: seven Lymphoedema Specialists (LS), three Urology Consultants (UC), and nine male patients who had received treatment for genito-urinary cancer: 7 of whom had a diagnosis of lymphoedema and 2 who had not been diagnosed as having lymphoedema.

The overall view from urology and lymphoedema experts, and from patients who have been treated for genito-urinary cancer, was that the development and application of such a tool was of value for identifying previously undetected or 'neglected' lymphoedema. This was associated with a perception of an underlying need to raise the awareness of patients and health professionals to the possibility of problems with persistent oedema (lymphoedema) after some genito-urinary cancer treatments. That is, swelling which persists beyond the expected acute oedema of some cancer treatments such as surgery. The tool was seen as particularly helpful in enabling men to voice concern over swelling persisting, or arising later, in the genitals.

Regarding the timing of the first use of the LGUCQ, a combination of UC expert opinion and patient experience would indicate that it would be appropriate in most cases to first give the LGUCQ to patients at their outpatient appointment after at least 4 weeks, but before 3 months, and that the initial instructions on the tool should reflect this. There should also be information that oedema is likely to settle within first few months. If problems are identified it could then be used as a monitoring tool. However, the findings would suggest that it should also be used in response to patient prompt thereafter. It is accepted that there may be exceptional or psychological reasons to delaying the questionnaire beyond 3 months but there appears little empirical evidence for this. The suggestion by one consultant to use the 
tool, even initially, only when triggered by a patient describing such problems was rejected on the basis that it would not improve current situation.

Enabling early identification was generally perceived as resulting in timely access to appropriate management. This was not universally experienced among the patients however. If, when a patient expressed concern regarding oedema they had experienced a lack of appropriate and/or timely response, understandably they were more likely to say that such a tool would not have made a difference to their care. Associated to this, two consultants described that mild oedema was unlikely be paid attention by health professionals, with only the 'bad' patients being referred to a specialist clinic. For the patients the link between identification of lymphoedema and then advice or action was essential. This suggests an education need in the health care professionals of self-management advice to give affected patients and the benefit of early referral to specialist lymphoedema services in their locality, where these exist.

The specific changes, in response to the interviews, to the format of prototype version of the questionnaire included:

a) The addition of reassuring information about some temporary oedema being normal to the heading and introductory paragraph and that advice on treatment is available should it persist.

b) Specific format changes to the diagram and some questions included some changes to the use of language to enhance clarity

c) The addition of questions relating to clothes, infections, and the advice/information received to date about lymphoedema and whether more information is needed.

d) The consolidation of several questions on quality of life into one open, global question.

\section{In response to participant feedback, the second iteration of LGUCQ was produced} (Appendix 1). 


\section{Recommendations}

\begin{tabular}{|c|l|}
\hline 1 & $\begin{array}{l}\text { The Lymphoedema Genito-Urinary Cancer Questionnaire (LGUCQ) } \\
\text { should be developed further and evaluated in a larger study with a view } \\
\text { to early identification of lymphoedema, improving patient care and } \\
\text { ascertaining greater accuracy as to the incidence of lymphoedema after } \\
\text { genito-urinary cancer. }\end{array}$ \\
\hline 2 & $\begin{array}{l}\text { The LGUCQ should be first used over } 4 \text { weeks after surgery (or the end } \\
\text { of other cancer treatment) and continued as a monitoring tool if } \\
\text { symptoms are identified. In addition it should be used at a later date if } \\
\text { prompted by the patient reporting a new problem of swelling. }\end{array}$ \\
\hline 4 & $\begin{array}{l}\text { Additional written information specific to this group of patients should } \\
\text { be available (leaflet/online) regarding the self-management of } \\
\text { Iymphoedema and access to specialist services }\end{array}$ \\
\hline 5 & $\begin{array}{l}\text { Education should be available for HCP in order to identify those at risk } \\
\text { of lymphoedema and in diagnosing lymphoedema. HCP working with } \\
\text { this patient group should be familiar with the patient information and } \\
\text { services available. }\end{array}$ \\
\hline
\end{tabular}

\section{Further research}

This study has potential for development with outputs which would be of interest to patients, clinicians and academics. Questions include:

- what is the sensitivity and specificity of this questionnaire?

o With what accuracy does the questionnaire accurately identify patients with and without lymphoedema 
o for which subgroups of patients would the questionnaire be most useful and least useful?

o Is there a difference in sensitivity with obese or underweight patients compared to normal weight range?

o can the scoring be used as a meaningful tool for monitoring genito-urinary cancer related lymphoedema?

o can the questionnaire be used to identify the incidence figures for lymphoedema from different types of genito-urinary cancers?

- Are there treatment outcome differences if the questionnaire is given to patients at different points in the genito-urinary cancer treatment journey?

- is there a group of other cancer, or non-cancer genito-urinary, surgery patients for whom this questionnaire would be useful?

\section{Summary}

This study has produced a short self-report tool for detecting male genito-urinary related lymphoedema by incorporating existing evidence with patient and practitioner views. This tool has the potential to improve patient care through the early identification and management of symptoms of lymphoedema. If used routinely in the clinical setting it also has the potential for providing evidence of the true incidence, prevalence and severity of lymphoedema after genito-urinary cancer.

Further research is required in the clinical setting to establish the sensitivity and specificity of the LGUCQ tool. In addition the most appropriate and effective timing of administrating the tool should be tested. The perceived utility of providing supporting literature with the selfreport tool could also be trialled. 


\section{References}

Armer J M, Radina ME, Porock D, Culbertson SD (2003) P redicting breast cancer-related lymphedema using self-reported symptoms. Nurs Res 52(6): 370-9

Bernas M (2013) Assessment and R isk Reduction in Lymphedema. Semin Oncol Nurs 29(1):12-9. doi: 10.1016/j.soncn.2012.11.003

Carter J , Raviv L, Appollo K, Baser RE, Iasonos A, Barakat RR (2010) A pilot study using the Gynecologic Cancer Lymphedema Questionnaire (GCLQ) as a clinical care tool to identify lower extremity lymphedema in gynecologic cancer survivors. Gynecol Oncol 117(2):317-23. doi: 10.1016/j.ygyno.2010.01.022

Cormier J N, Askew RL, Mungovan KS, Xing Y, Ross MI, Armer J M (2010) Lymphedema beyond breast cancer: a systematic review and meta-analysis of cancer-related secondary lymphedema. Cancer 116: 5138-49. doi: 10.1002/cncr.25458

Cowher MS, Grobmyer SR, Lyons J , O'R ourke C, Baynes D, Crowe J P,(2014) Conservative axillary surgery in breast cancer patients undergoing mastectomy: long-term results. J Am Coll Surg 218(4):819-24. doi: 10.1016/j.jamcollsurg.2013.12.041

Garaffa G, Christopher N, Ralph DJ (2008) The management of genital lymphoedema. BJ U Int 102(4): 480-4. doi: 10.1111/j.1464-410X.2008.07559.x

G ilbert SM, Wood DP, Dunn RL et al (2007) Measuring health-related quality of life outcomes in bladder cancer patients using the Bladder Cancer Index (BCI). Cancer 109(9): 1756-62

International Society of Lymphology (2003) The diagnosis and treatment of peripheral lymphedema. Consensus document of the International Society of Lymphology. Lymphology 36(2):84-91

Langbecker D, Hayes SC, Newmann B, J anda M (2008) Treatment for upper and lower limb lymphedema by professionals specializing in lymphedema care. Eur J Cancer Care (Engl) 17 (6): 557-64 doi: 10.1111/j.1365-2354.2007.00878.x.

Morgan PA, Franks PJ , Moffatt CJ (2005) Health-related quality of life with lymphoedema: a review of the literature. Int Wound J 2(1):47-62

Okeke AA, Bates DO, Gillatt DA (2004) Lymphoedema in urological cancer. Eur Urol 45: 1825

Pope C, Ziebland S, Mays N (2000) Qualitative research in health care: analysing qualitative data. BMJ 320(7227): 114-6

Ridner SH (2006) Pretreatment lymphedema education and identified educational resources in breast cancer patients. Patient Educ Couns 61(1):72-9

Rimouche S, Ball S, Kumar $P$ et al (2013) Key factors in reducing mobidity after inguinal node dissections. European J ournal of Plastic Surgery 36(3): 171-8. doi:10.1007/s00238012-0757-4 
Rockson SG (2008) Diagnosis and management of lymphatic vascular disease. J Am Coll Cardiol 52(10):799-806. doi: 10.1016/j.jacc.2008.06.005

Rockson SG (2009) The unique biology of lymphatic edema. Lymphat Res Biol 7(2):97-100. doi: $10.1089 / / r b .2009 .7202$

Rockson SG (2012) Update on the biology and treatment of lymphedema. Curr Treat Options Cardiovasc Med 14(2):184-92. doi: 10.1007/s11936-012-0170-0

Sakorafas GH, Peros G (2007) Sentinel lymph node biopsy in breast cancer: what a physician should know, a decade after its introduction in clinical practice. Eur J Cancer Care (Engl) 16(4):318-21

Stout NL, Pfalzer LA, S pringer B et al (2012) Breast cancer-related lymphedema: comparing direct costs of a prospective surveillance model and a traditional model of care. Phys Ther 92(1):152-63. doi: 10.2522/ptj.20100167. Epub 2011

Stout Gergich NL, Pfalzer LA, McGarvey C, Springer B, Gerber LH, Soballe P (2008) Preoperative assessment enables the early diagnosis and successful treatment of lymphedema. Cancer 112(12):2809-19. doi: 10.1002/cncr.23494

Todd J , Harding J , Green T (2010) Helping patients self-manage their lymphoedema. J ournal of Lymphoedema 5(1): 91-6. http://tinyurl.com/mbuznpp (accessed 24 September 2014)

Torres Lacomba M, Yuste Sánchez MJ , Zapico Goñi A et al (2010) Effectiveness of early physiotherapy to prevent lymphoedema after surgery for breast cancer: randomised, single blinded, clinical trial. BMJ 340:b5396. doi:10.1136/bmj.b5396

Viehoff PB, Hidding JT, Heerkens YF, van Ravensberg CD, Neumann HA (2013) Coding of meaningful concepts in lymphedema-specific questionnaires with the ICF. Disabil Rehabil 35(25):2105-12. doi: 10.3109/09638288.2013.771710

W itty K, Branney P, Bullen K, W hite A, Evans J , Eardley I (2014) Engaging men with penile cancer in qualitative research: reflections from an interview-based study. Nurse Res 21(3):13-9. doi: 10.7748/nr2014.01.21.3.13.e1218

Yost KJ , Cheville AL, Weaver AL, Hilli MA, Dowdy SC (2013) Development and validation of a self- report lower-extremity lymphedema screening questionnaire for women. Phys Ther 93(5):694-703. doi: 10.2522/ptj.20120088. 


\section{Appendix 1. Lymphoedema Genito-urinary cancer Questionnaire}

\section{Self-completion questionnaire for men treated for cancer of the bladder, prostate or genitals (penis or scrotum) and over 4 weeks since completion of treatment.}

\section{Full Name}

Date:

Swelling in the legs / genitals can be quite normal for a few weeks after some types of cancer treatment. Your consultant will have already discussed with you if there are any expected long term changes to the shape of your body or to the feeling (sensation) of the skin. This questionnaire is to help identify swelling which is not settling down and was not present before the cancer treatment; or which has only appeared recently. Persistent swelling like this can be a condition called lymphoedema which is easiest to manage if reported early. Please complete the questions below to help us give you the appropriate advice and care.

\begin{tabular}{|c|c|c|c|c|c|}
\hline \multicolumn{2}{|c|}{$\begin{array}{l}\text { Changes in your lower body since your } \\
\text { cancer treatment }\end{array}$} & $\begin{array}{c}\text { Not at } \\
\text { all } \\
\text { (or not } \\
\text { relevant) } \\
\mathbf{0}\end{array}$ & $\begin{array}{c}\text { A } \\
\text { little } \\
\text { bit } \\
1\end{array}$ & $\begin{array}{c}\text { Quite a } \\
\text { bit } \\
\\
2\end{array}$ & $\begin{array}{c}\text { Very } \\
\text { much } \\
\\
3\end{array}$ \\
\hline & (for example) & & - & & \\
\hline \multirow[t]{2}{*}{ I have swelling: } & in my leg(s) & & & & \\
\hline & in my genitals & & & & \\
\hline \multicolumn{6}{|c|}{$\begin{array}{l}\text { If you feel you have no swelling at all you do not need to complete the rest of this } \\
\text { questionnaire. }\end{array}$} \\
\hline \multicolumn{6}{|c|}{ The swelling is noticeably more by the end of the day } \\
\hline \multirow[t]{6}{*}{ The swelling is affecting: } & $\begin{array}{l}\text { which clothes/shoes I can } \\
\text { wear }\end{array}$ & & & & \\
\hline & my sitting & & & & \\
\hline & getting in/out of bed & & & & \\
\hline & my walking & & & & \\
\hline & passing urine & & & & \\
\hline & my sexual function & & & & \\
\hline \multirow{4}{*}{$\begin{array}{l}\text { The skin around the } \\
\text { swollen area: }\end{array}$} & feels tight & & & & \\
\hline & has changed colour & & & & \\
\hline & feels different & & & & \\
\hline & feels wet/cold & & & & \\
\hline \multirow{2}{*}{$\begin{array}{l}\text { The swelling gives me } \\
\text { discomfort: }\end{array}$} & in my leg(s) & & & & \\
\hline & in my genitals & & & & \\
\hline \multicolumn{6}{|c|}{ I need to take painkillers for the discomfort } \\
\hline \multirow{2}{*}{\multicolumn{4}{|c|}{$\begin{array}{l}\text { During this period have you needed antibiotics for infections } \\
\text { (cellulitis) in your leg(s) or genitals? }\end{array}$}} & Yes & No \\
\hline & & & & & \\
\hline \multicolumn{2}{|c|}{ If yes, how many times has this happened? } & & & & \\
\hline
\end{tabular}




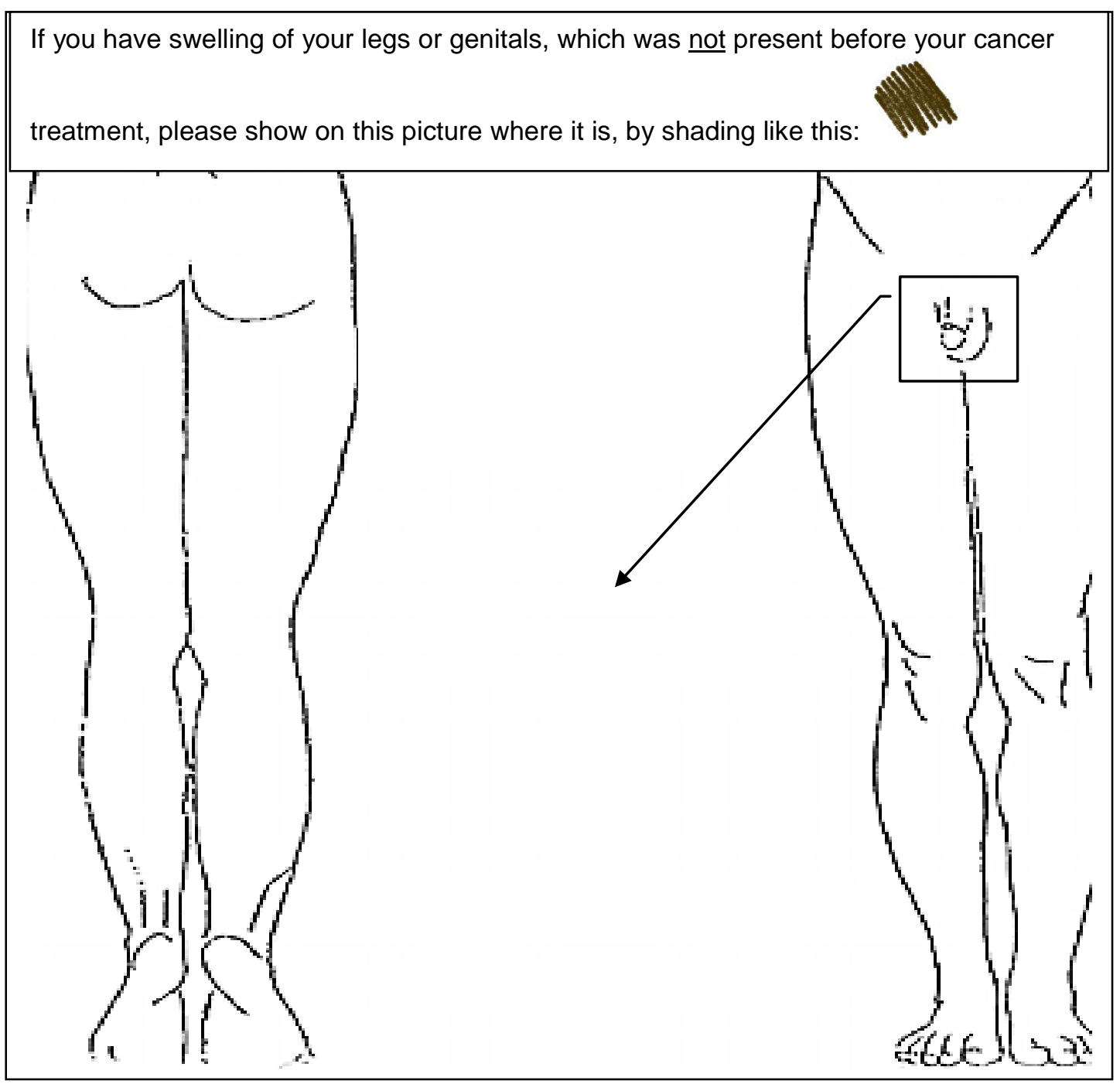

\begin{tabular}{|l|l|l|l|}
\hline On average this week how severe has the swelling been? \\
\hline $0=$ No swelling & $1=$ a little bit & $2=$ quite a bit & $3=$ very swollen \\
\hline & & & \\
\hline
\end{tabular}

Is there anything else you would like to tell us about how this is affecting you physically or emotionally?

\begin{tabular}{|l|l|l|}
\hline $\begin{array}{l}\text { Have you been offered any advice or treatment for } \\
\text { lymphoedema (swelling)? }\end{array}$ & Yes & No \\
\hline Would you like any information or advice? & & \\
\hline
\end{tabular}

